\title{
UNA PROPUESTA PARA EL ESTUDIO DE LA FO'TOHISTORIA: EL MÉTODO ICONOGRÁFICO
}

\author{
CONCHa Gasa.jús
}

Profesora de Teoría Y Técnica de la Fotografía. Universidad San Pablo-Ceu de Madrid

\section{Resumen}

La trascendencia que ha tenido y tiene la fotografía es ya un hecho indiscutible para todos. Vivimos en "el tiempo de la imagen". Sin embargo, el análisis del significado de las imágenes fijas es una disciplina relativamente nueva a nivel internacional y todavía mucho más reciente a nivel nacional -su implantación como asignatura universitaria en España apenas alcanza una década. La problemática deriva de las cantidades ingentes de fotografías, de la ausencia o juventud de las teorías y de los métodos de estudio y de las discrepancias entre teóricos debidas a la escasez de encuentros nacionales e internacionales. Todo ello dificulta el desarrollo de una fotohistoria aceptada por todos. Trato, en este caso, de proponer un método de estudio, el método iconográfico, que, partiendo de los elementos específicos del lenguaje fotográfico y de las necesarias diferencias de tratamiento que imponen los distintos géneros fotográficos, pueda abordar con rigor el problema de la selección y posterior profundización en las imágenes que constituyen la fotohistoria.

\section{Palabras clave}

Elementos específicos, géneros, análisis de la imagen fotográfica, fotohistoria, método de estudio.

\section{Abstract}

The impact, past and present, of photography is nowadays an indisputable fact for each and all of us. Despite the fact that we are living in the "Age of Image", the analysis of the meaning of static pictures is an almost new field worldwide and even newer at national level: in fact it was introduced as a subject in Spanish Universities scarcely ten years ago. The problem arises from huge amounts of photographs, lack or inadequacy of theories and study methods, and disagreement among theoreticians caused by insufficient national or international conferences. All of this hinders the development of a "photo-history" which is universally accepted. In this work a methodology for study is proposed which is called "iconographic methodology". It attempts to rigorously approach the problem of selection and subsequent in-depth analysis of the images that are constituents of photo-history. It does so by starting with the different specific elements of photographic language and those differences in treatment required by the various photographic genres.

Key Words

Specific elements, genre, photographic image analysis, photo-history, study methodology 


\section{INTRODUCCIÓN}

La fotografía ha modificado nuestra visión, nos ha traído imágenes lejanas en el espacio, ha hecho visible lo que era físicamente invisible, transformando nuestra percepción del espacio y del tiempo. Ha contribuido, además, a la expansión y popularización de la cultura, al desarrollo de los medios de comunicación de masas y ha configurado un lenguaje propio, básicamente comprensible para toda la humanidad.

No conviene olvidar, por otro lado, su aportación a la enseñanza de "la verdad". En este sentido, debemos ser conscientes de que en una época en que lo manuscrito se ha reducido alarmantemente o ha sido destruido por comprometedor, lo fotografiado va a ser fundamental para reconstruir la historia.

Su valor documental y testimonial, su capacidad de comunicación y de persuasión, su presencia expansiva en multitud de áreas de conocimiento y en la vida cotidiana, son realidades incuestionables que hacen necesaria una mayor profundización en el estudio de la imagen.

Vivimos rodeados de imágenes fotograbadas -fijas, cinéticas, digitales- que van configurando parte de nuestra realidad; son imágenes testimoniales, vendedoras, suplantadoras y virtuales, cuya actividad se multiplica al mismo ritmo vertiginoso al que evoluciona la tecnología.

Precisamente por todo ello, ante esta enorme avalancha de información visual no hay tiempo físico ni psíquico para asimilar y se hace necesario superar la fase de información para pasar a otra de formación. Esto nos permitiría seleccionar, abrir un paréntesis temporal y encontrar un método de reflexión que nos condujera a lo esencial, y así poder compararlo y sacar nuestras propias conclusiones; solo así podremos desarrollar nuestra capacidad crítica y madurar como humanistas.

La cantidad, por tanto, es parte esencial y diferenciadora del hecho fotográfico y de ella se deriva otra realidad: las grandes diferencias en la calidad de las imágenes. Aunque todavía persistan tópicos entre la multitud, como el de "cualquiera puede hacerlo", en el caso de determinadas manifestaciones fotográficas es imprescindible escuchar a la multitud.

Imágenes, por otro lado, puestas al servicio de actividades útiles de todo tipo -comerciales, culturales, científicas, lúdicas, informativas- que, como múltiples manifestaciones claramente diferenciadas, han dado lugar a distintas divisiones en grupos o géneros, los cuales todavía coexisten, ya que los teóricos no hemos llegado a un consenso general. Sin embargo, a finales de los años 90 del siglo XX, Michel Frizot, profesor de Historia de la Fotografía de la Escuela del Louvre de París, habla de las fotografías, no de la fotografía y nos lanza a la revisión internacional de la fotohistoria, al proponer un nuevo análisis y una nueva historia: la historia de las fotografías. Así, de alguna manera, reuniendo las aportaciones de los especialistas en cada fotografía se podrían superar las complicaciones derivadas del reconocido carácter interdisciplinar de la materia (Frizot, 2002). 
Esta revisión debe crecer en rigor y universalizarse, porque la fotohistoria realizada hasta ahora ha reconstruido la evolución de la fotografía en cada país y la competencia originó la exclusión de fuentes, que se eludieran determinadas lagunas y que se aplicaran en cada caso metodologías muy diferentes. Con todo ello el resultado obtenido es muy irregular.

Este panorama, además, viene a complicarse a causa de la presión ejercida por la rápida evolución de las nuevas tecnologías. Lo que les pasa a las fotografías analógicas, que siguen vivas químicamente aunque se les da por concluidas, se puede hacer extensible al resto de las imágenes fotográficas: su percepción puede variar en función del contexto físico e informático en el que se inscriban.

Llegados a este punto parecía imprescindible, y a veces imposible (Durand, 1999), encontrar un método de investigación que nos permitiera abordar de la manera más racional posible el estudio de las distintas fotografías; un método que nos ayudara, además, a reducir el numero de imágenes seleccionadas para su posterior análisis. Para abordar todo ello se hace necesario abordar, aunque sea muy rápidamente, una serie de premisas y conceptos fotográficos por los que hemos optado.

\section{PREMISAS Y CONCEPTOS FOTOGRÁFICOS}

Entendemos que la fotografía ha generado uno de los lenguajes visuales nacidos y desarrollados en la historia contemporánea. Es un lenguaje universal y que tiene gran capacidad de descripción, narración, opinión y persuasión. Éste posee, además, unos caracteres específicos que lo diferencian de otros lenguajes visuales, ya que le otorgamos un importantísimo valor documental por ser "testigo" y "memoria" de los grandes y pequeños acontecimientos, de lo público y de buena parte de lo privado (de no ser por ella se hubiera perdido) y también de las distintas formas de vida y pensamiento. Por otro lado, una parte de la fotografía posee un importante valor plástico y estético y ha aportado novedades creativas a la evolución de la Historia del Arte. Pero las distintas manifestaciones fotográficas como nuevo fenómeno de captación y representación del mundo con una diferente y profunda temporalidad han sido el motor que impulsó la aparición y desarrollo de las vanguardias artísticas y de otros medios de comunicación de masas.

La fotografía está muy relacionada con la máquina, el proceso industrial y los sistemas de comunicación de masas. El análisis de estos tres aspectos fundamentales es conveniente si queremos realizar un estudio iconográfico y comprender el significado de las imágenes.

Imágenes con valor comunicativo y documental, que poseen un lenguaje específicamente fotográfico y con cierta capacidad de innovación artística, son las que más interesan a la crítica, a la historiografía y a la investigación. Son las imágenes que merece la pena salvar de entre ese mare magnum de fotografías que produce el mundo actual (millones por minuto) y que plantean serios problemas de visualización, selección y archivo (sino que se lo cuenten a Bill Gates que pretende habilitar una enorme y antigua mina).

Antes de pasar a describir el método iconográfico, se deberá abordar el tema de los distintos géneros y subgéneros fotográficos, ya que son muchas y muy variadas las imágenes que hay 
que agrupar y subdividir, porque su tratamiento variará en función del género al que pertenezcan y porque no hay consenso entre los teóricos.

\section{LOS DISTINTOS GÉNEROS FOTOGRÁFICOS}

Hablar de géneros fotográficos es entrar en lo que Gillo Dorfles llamó en 1989 "fotografía sin luz", aunque él empleara el término refiriéndose a otras cuestiones, es decir, que nos estamos introduciendo en un mundo de sombras o, mejor dicho, en un mundo de contraluces en el que, más que sistematizar, se suele intuir o presuponer, con el consiguiente riesgo de caer en contradicciones.

Seguramente, y por pura necesidad, fueron los concursos fotográficos los primeros en establecer distintas categorías que nunca competían entre sí. Lo malo es que cada concurso agrupa de manera diferente, porque no existen líneas directrices fijas. Únicamente la fotografía publicitaria y la de prensa aparecen claramente diferenciadas, ya que exigen especialización dentro de la profesión.

En la bibliografía en la que predomina lo técnico las imágenes suelen estar agrupadas según los procedimientos de realización (Langford, 1996; Fontcuberta). Los teóricos del Arte separan por temas o por corrientes estéticas comparadas con la pintura (Stelzer, 1981). Pero en ambos casos, a nivel de conceptos, se sigue tratando a la fotografía como si fuera un bloque compacto.

José Manuel Susperregui organiza las imágenes fotográficas en cinco grandes grupos: fotografía artística, fotografía documental, fotografía de prensa, fotografía de moda y fotografía publicitaria (1988). Sin embargo, todavía queda una gran cantidad de manifestaciones sin organizar.

Existen otros ensayos que abordan algún género en particular, como los de Lorenzo Vilches (1987), Margarita Ledo (1988), Peter Burke (2001), Joan Fontcuberta (1997) y Pepe Baeza (2001) y que han ido profundizando en la fotografía de prensa, en el documentalismo fotográfico y en el uso de la imagen como documento histórico.

Pero hasta 1998, cuando Michel Frizot publica A New History of Photography, no se habla de las fotografías y es él quien establece una serie de grupos relativamente nuevos, pero no define los criterios que generan la aparición de dichos agrupamientos y no de otros. Las distintas fotografías parecen nacer de las diferentes formas de la aplicación práctica de la fotografía, de la evolución teórica, de los usos y costumbres. Parece una estructura lógica y natural, pero carece de justificación. No obstante, como se acerca bastante a la división en géneros que establecí en 1985 y que continúo revisando me parece oportuno introducirla aquí resumida (Casajús, 1998) para evitar equívocos a la hora de distribuir las imágenes.

\section{¿POR QUÉ GÉNEROS EN VEZ DE GRUPOS?}

Género es un término utilizado tradicionalmente en distintas manifestaciones artísticas. En pintura tuvo un cierto tono peyorativo cuando en el siglo XVII se aplicó a los "bambochantes", sin embargo, en literatura sirvió para agrupar obras semejantes entre sí. 
La utilización del término género se considera más explícito, ya que incluye la idea de grupo, y más adecuada, porque las comparaciones que se irán estableciendo con la estructura literaria deben quedar de alguna forma reflejadas. Por otro lado, el uso de la terminología literaria es un hábito común.

\section{CRITERIOS DE DIVISIÓN}

Ahora hay que establecer los elementos estructurales que marcan la división y que van a definir las diferencias entre los distintos géneros.

La mayor parte de las fotografías que se consideran interesantes fueron realizadas pensando que podrían tener una utilidad pública, pero no debemos olvidar las imágenes que se ejecutaron con fines exclusivamente privados. Esto marca una primera división (véase esquema).

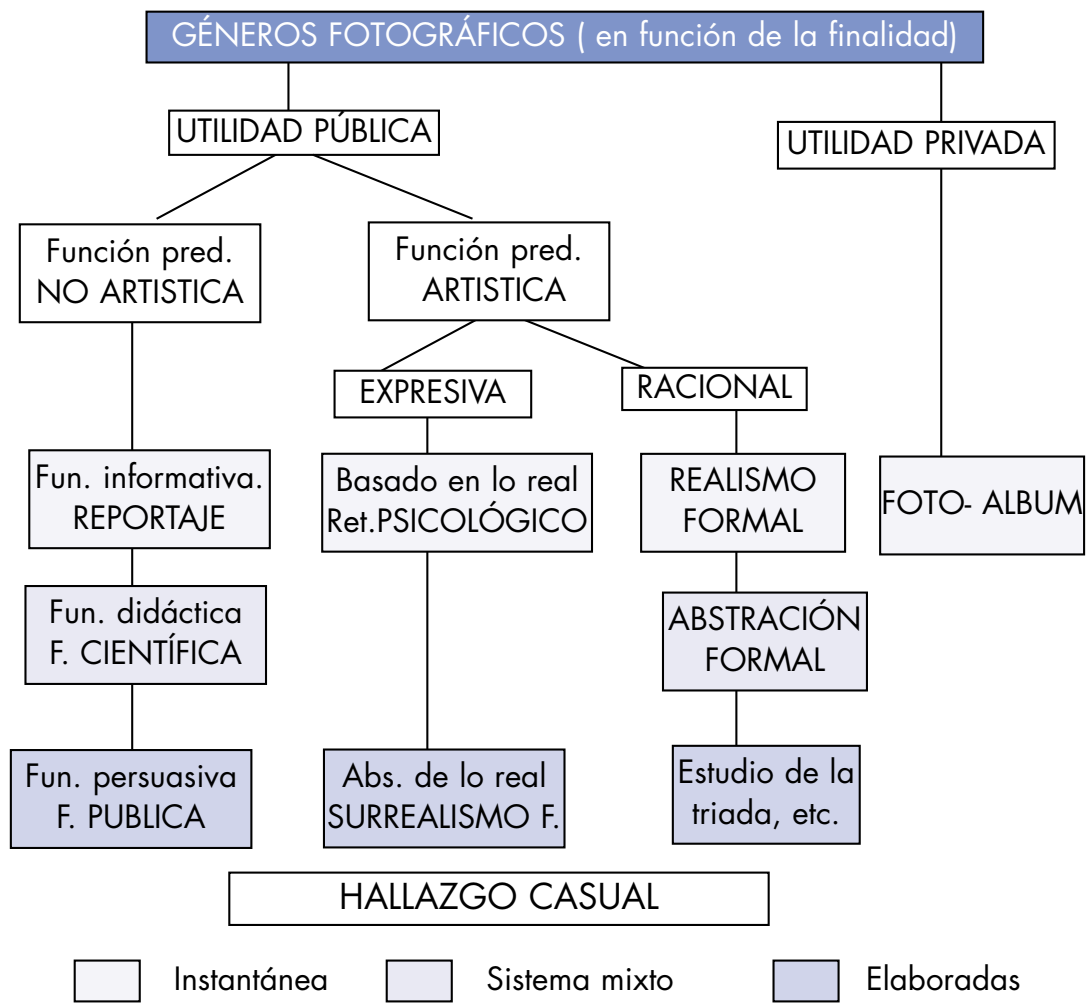

Cuadro resumen de los géneros fotográficos. Para ampliar información consultar capitulo 6 de Manual de Arte y Fotografía: C. Casajús, E. Universitas SA., Madrid, 1998. 
En este sentido, el fin con que fue tomada una imagen, así como la utilización que se le dará, determinan, en la mayoría de los casos, el aspecto de la imagen y el grado de libertad formal e ideológica del fotógrafo, así como la expresión o represión de sus sentimientos.

Las funciones fundamentales que influyen en la génesis de las fotografías son las siguientes: informativa, didáctica, persuasiva y estética. Dentro de la estética, la fotografía puede seguir, a su vez, dos líneas: la racional y la que expresa sentimientos.

El tercer factor que interviene en la estructuración se refiere al grado de elaboración de la imagen y va desde una gran dificultad a la hora de la realización por la complicación técnica y el despliegue de medios, hasta la instantánea que es muy rápida de ejecución, pero que puede exigir un desarrollo excepcional de las capacidades fotográficas. Este tercer factor está relacionado con la naturalidad de las imágenes. No siempre elaboración quiere decir artisticidad o irrealidad y no siempre instantaneidad implica realidad o algo específicamente fotográfico.

\section{LOS GÉNEROS FOTOGRÁFICOS}

Dentro de la gran masa de fotografías que fueron realizadas para que en algún momento pudieran ser disfrutadas por el público se pueden establecer dos grupos: aquellas fotos en las que la función predominante no es artística y aquellas en las que predomina la función estética:

\section{Función pública y predominantemente no artística:}

Que la función predominante no sea estética no quiere decir que el aspecto formal se descuide, sino que está condicionado por otros imperativos. Dentro de este grupo aparece la posibilidad de establecer tres géneros: la fotografía científica, la fotografía de prensa y la fotografía publicitaria.

\section{Fotografía científica}

Es fundamentalmente descriptiva. En ella el fotógrafo no incluye sus sentimientos.

Su finalidad fundamental es enseñar, demostrar algo. Por eso, comparándola con los géneros literarios, se puede decir que está cerca de la didáctica.

Exige una larga elaboración a nivel de preparación pero se realiza instantáneamente. Se detiene el instante para una exploración profunda, lenta y penetrante.

Debe ser clara y limpia, pero la artisticidad es secundaria frente al propósito investigador, aquí no importa el autor ni mucho menos su estilo. Todo se subordina a su función pedagógica. 
Fotografía de prensa

En fotoperiodismo el fotógrafo actúa seleccionando imágenes instantáneas que recogen acontecimientos humanos.

Subordina la expresión directa de sus sentimientos a los de sus modelos. Ellos son los protagonistas. Los sentimientos del operador se pueden intuir por los motivos seleccionados, pero lo que la imagen realmente expresa es lo que en ella aparece representado.

No obstante, los hechos del hombre son interpretables igual que en el género histórico.

Aquí sí está presente la personalidad del autor que fragmenta la realidad, ofreciéndonos una parte. Aquí puede hablarse de estilo.

Hay distintos subgéneros dentro de la fotografía de prensa.

La función predominante es la informativa, aunque puede opinar. Está estrechamente ligada al texto y al contexto, pero, cuando pierde su dependencia del texto y de la demanda del cliente, puede alcanzar niveles importantísimos de creatividad y artisticidad.

\section{Fotografía publicitaria}

El fotógrafo publicitario subordina su ideología y su técnica a una finalidad: la de persuadir al espectador. Por eso se puede comparar la oratoria de los géneros literarios.

Casi nunca es una imagen instantánea, sino elaborada, pensada, y que tiene en cuenta la psicología del espectador y la sociología del consumo. Técnicamente usa: trucos, fotomontaje, iluminaciones especiales o connotaciones estilísticas de otras artes.

No le importa ser artificial, si con ello persuade. Puede ser teatral y creadora de espacios y formas nuevas, o desagradable, vulgar y "kitsh", si con ello convence al espectador.

La imaginación y la personalidad estética del autor salen a flote: la forma es del fotógrafo, pero no olvidemos que el tema y el fondo nunca proceden del operador.

En publicidad no se puede prescindir de la subordinación al texto.

\section{Función pública predominantemente estética (Fotografía artística)}

De este bloque de imágenes se pueden hacer muchos grupos en torno a dos vías que caminan paralelas. La primera vía es la que expresa los sentimientos del autor y la otra es la racional. En ambas se puede desarrollar la personalidad e inquietudes del autor con un grado elevado de libertad (el máximo en fotografía), ya que no tiene que subordinarse ni al texto ni al espectador, aunque luego tenga problemas de comercialización. 
El autor se manifestará dando una nueva visión de la realidad, que puede ser real o inventada, dramática, cómica, irónica, crítica o laudatoria, en el caso de seguir la primera vía. Mientras que, si sigue la segunda, hará una investigación del espacio, del tiempo, del movimiento, del relieve o de cualquier otro aspecto formal, siempre con finalidad artística.

Pero en ambas tendencias, aunque la fotografía sea siempre más figurativa que la pintura debido a su reproducción mecánica, se puede ser fiel a lo real o abstraer. Se pueden producir imágenes instantáneas o muy elaboradas.

\section{Vía expresionista:}

\section{Realismo psicológico}

Cuando el fotógrafo se aproxima a la realidad y ésta continúa siendo figurativa y manifestando las sensaciones del autor.

Siguiendo las tres temáticas fundamentales -personas, naturaleza y cosas-, producirá retratos y paisajes psicológicos, y bodegones simbolistas. instantánea.

\section{Abstracción surrealista}

Cuando la imagen se aleja de la copia de la realidad y crea ambientes expresivos nuevos, en donde se desenvuelven las personas, la naturaleza y las cosas, a través de una larga elaboración que incluye determinados los trucos, estamos frente al retrato surrealista, paisaje surrealista y bodegón surrealista.

\section{Vía racionalista:}

\section{Realismo formal}

Cuando se hace una investigación de forma, textura, luz, cromática, perspectiva, composición o encuadre sin abstraer la realidad y sin expresar sentimientos del autor.

El aprisionamiento de la imagen debe ser rápido.

Si se sigue la temática fundamental, las imágenes se podrán calificar como retrato real, paisaje real y bodegón real. 


\section{Fotografía abstracta}

Siempre que la forma sea abstraída hasta el punto de llegar a perder la conexión con el modelo que la originó.

Su realización no es instantánea ya que exige una larga búsqueda. Pero este grupo tampoco admite una complicada manipulación, sino una captación final instantánea. Porque si se llega a una abstracción total por manipulación, estaremos ante algo que no es ya fotografía pura.

\section{Fotografía artístico-científica}

Cuando la investigación estudia el espacio, el tiempo, el movimiento y el relieve de una forma filosófico-científica y con una finalidad estética. Se crearán nuevas formas de ver la realidad después de un largo proceso de elaboración donde no importa abstraer una parte siempre que no se pierda el contacto con la realidad.

La fotografía artístico-científica incluye la estereoscopia, el holograma y el diaporama.

\section{Hallazgo casual (Costa, 1977)}

Hay un pequeño grupo de fotografías consideradas artísticas, por ser muy estéticas, en donde no hubo búsquedas expresivas, ni racionales por parte del autor, ni le supusieron esfuerzo ni tiempo el producirlas.

Estas fotos pueden presentar imágenes totalmente fieles a la realidad o abstracciones puras. Suelen ser puntos de partida de distintas búsquedas estéticas y son algo muy característico de la fotografía.

\section{Función privada y particular: el foto-álbum}

Hasta ahora las fotografías que se han ido viendo fueron presentadas y dirigidas al público en general. Este último grupo de imágenes sólo serán visualizadas por unas pocas personas. Su autor es amateur y las produce para divertirse, para tener un recuerdo o como una forma de participar en ciertos acontecimientos (Sontang, 1990).

Las imágenes de aficionados del álbum familiar suelen ser instantáneas y poco creativas. $\mathrm{Si}$ las comparamos con la literatura, encontraremos el paralelismo con el diario y las cartas privadas.

Como fuentes documentales son curiosas e interesantes, ya que reflejan la vida cotidiana de cada época. Completan la visión del mundo que ofrecen las otras fotografías en busca de lo raro.

La calidad técnica no es buena. Pero tienen un lenguaje con constantes a lo largo del tiempo y una personalidad anónima pero generalizada e, incluso, una iconografía característica. 
No hay autores, pero sí lenguaje. No es muy creativo, pero sí descriptivo. Cubren su parcela de realidad. Pero esto no se puede dejar de lado.

El álbum familiar y la fotografía amateur vienen a ser la popularización de la técnica, algo equivalente a las canciones o la arquitectura popular y que, salvaguardando la auténtica personalidad de un pueblo o su funcionalidad, pueden volver a influir sobre los grandes creadores.

\section{MÉTODO ICONOGRÁFICO}

Hemos visto que para poder reconstruir la historia de la/s fotografía/s habrá que seleccionar las imágenes y agruparlas y, para ello, no tendremos más remedio que analizar el significado de las mismas, es decir, necesitamos un método de investigación que nos ayude a hacerlo de la manera más racional posible. Lo he llamado el método iconográfico, aunque soy consciente de que la novedad, complejidad y búsqueda del rigor hacen que pueda y deba perfeccionarse.

¿Por qué lo llamo iconográfico? Icono significa imagen. La imagen siempre es un reflejo y en este caso concreto un reflejo de la realidad, porque aquí la relación con la realidad es fundamental, ya que la realidad puede ser fielmente reproducida o seleccionada y representada, interpretada, dramatizada o abstraída, en cualquier caso seguirá un lenguaje que puede ser específicamente fotográfico, como muy bien ha demostrado Joan Costa (1991), y que va encaminado a transmitir un mensaje al espectador, es decir, que se entra de lleno en un proceso de comunicación.

Gráfico viene de grafos, que alude a grabar, y, en el caso de la fotografía, se hace con luz, obteniendo una imagen estática que detiene el tiempo y que es capaz de significar, expresar o representar algo de una determinada manera.

El método iconográfico nos permitiría hacer un estudio del significado de estas imágenes no cinéticas grabadas con luz y seleccionar aquellas que se han convertido en un símbolo por lo que comunican o por lo que aportan creativamente.

¿De dónde viene? y ¿̇a dónde va? El estudio los lenguajes visuales, en el caso concreto de la fotografía, no lleva tanto tiempo desarrollándose y estudiándose como en los lenguajes orales y escritos. Por eso, una vez aceptado que estamos ante un nuevo lenguaje visual, ¿̇por qué no aprovechar las aportaciones de los que ya han estudiado racionalmente el significado y la articulación de los mensajes hablados? Eso es precisamente lo que he intentado hacer al traspasar la estructura del comentario de texto literario al análisis de cada fotografía, estructura que ha sido adaptada $y$, en algunas ocasiones, enriquecida por las características propias del hecho fotográfico. Así se evitaría, en todo momento, como hicieron algunos filólogos en la década de los setenta del pasado siglo, caer en irreales y peyorativas comparaciones. 
Sin embargo, a la hora de medir la creatividad o de perfilar de qué manera nos cuentan las imágenes fotográficas lo que aportaban los lenguajes orales y escritos resultaba insuficiente, entonces he recurrido a las diferentes metodologías que nos proporciona la Historia del Arte, que es el área de conocimiento que primero ha estudiado otros lenguajes visuales y de la que la fotografía ha recogido muchas características, aunque no las específicamente fotográficas.

Me han resultado especialmente reveladores e interesantes los estudios del desaparecido investigador alemán Otto Stelzer. En los cursos que impartió en la Escuela Estatal Superior de Artes de Hamburgo en los años sesenta afirmaba con contundencia que "la historia de la fotografía muestra, al igual que la historia del arte, un cambio de estilo y que éste, en sus rasgos esenciales, se desarrolla en consonancia con la pintura. Y ello condujo al juicio básicamente erróneo de que la fotografía persigue a la pintura... Pero he aquí que también existe una dependencia inversa. La fotografía ha influido por su parte en la pintura, "creando estilos", incitando y transformando, y es precisamente esta relación, estas influencias y consecuencias, lo que será objeto de nuestro estudio" (Stelzer, 1981: 11).

De Stelzer se desprende la idea de escribir la historia del arte contemporáneo "al revés", entendiendo que la fotografía había sido el detonante y el motor que propició la aparición de muchas de las vanguardias artísticas. Esta acción viene practicándose en Europa desde entonces y, como otros autores, he intentado trasladar al estudio de la fotohistoria.

¿En qué consiste? Dado, como ya se ha expuesto, que la imagen fotográfica es un reflejo de la realidad y que la relación con la misma es fundamental, porque constituye su propia esencia, reconstruirla y profundizar en la misma será el punto de arranque del proceso que se pretende iniciar. Para seguir una terminología muy enraizada con lo fotográfico he denominado a esta fase la inmersión en el tema.

La inmersión en el tema es el primer paso que debemos realizar en nuestro proceso de investigación. La lectura del desarrollo de los acontecimientos históricos, políticos, económicos y sociales estudiados por diferentes autores de distinta ideología es fundamental para establecer lo que caracteriza a una época.

Pero la inmersión en el tema también pasa por conocer las formas de vida y pensamiento que han coexistido, los usos y costumbres de la vida pública y privada. Y, en muchos casos, la transmisión de este conocimiento solo nos llega a través de manifestaciones "menos objetivas" y más interpretativas de la historia, como son la literatura, el cine, la prensa e, incluso, las cartas privadas o el álbum familiar.

La siguiente fase consistirá en establecer un marco de referencia general que servirá para ordenar y comparar. Para ello habrá que seleccionar los elementos que caracterizan a nivel internacional una etapa, incluyendo también la evolución de las distintas manifestaciones artísticas. 
Cuando la investigación sea a nivel nacional, autonómica o local, habrá que repetir el procedimiento, para posteriormente poder establecer una comparación entre el marco de referencia general y el nacional o local.

A continuación, se pasará a la selección de imágenes en función de que cumplan algunos de los criterios anteriormente establecidos: una capacidad comunicativa y documental que trasciende, poseer un lenguaje específicamente fotográfico o innovar artísticamente.

Después de realizar la selección de imágenes, habrá que analizar la forma y el contenido de cada una de ellas, con lo que se incluirán otras variables de influencia, como puedan ser la autoría o el contexto en que fueron realizadas o transmitidas y las reacciones que produjeron en los receptores. Todo esto es lo que finalmente nos permitirá acceder al auténtico significado de las mismas, a lo que aportan y porqué lo hacen.

\section{SISTEMA DE ANÁLISIS}

El "rastro" de la realidad, como la denomina Serge Tisseron (2000), percibida por el fotógrafo se hace visible, se expresa a través de una imagen fotográfica, en la cual forma y contenido son complementarios e interdependientes. Además, esta imagen, formal e ideológicamente, está inscrita en un contexto (periodístico, publicitario, expositivo, etc.) y puede combinarse con un texto escrito, y todo ello forma parte de un proceso de comunicación.

Por eso, para analizar la imagen y su contexto, el lenguaje que utiliza para transmitir el mensaje (contenido) y para expresarse, habrá que analizar los elementos y conceptos que caracterizan y configuran el lenguaje fotográfico (la forma) de la foto, aislada primero y en el contexto después, para pasar al siguiente tema a hablar de los contenidos.

\section{Análisis de la forma de la foto aislada}

La fotografía es imagen de la realidad. En su cosmos, el espacio, el tiempo y el movimiento adquieren unos caracteres diferentes a los de la triada real. Para analizar esta forma de expresión hay que enfrentarse a conceptos subjetivos: espacio, tiempo, movimiento, y a elementos objetivos como, por ejemplo, grano, textura, etc.

Habrá que comparar el espacio real y el espacio fotográfico partiendo de la idea de que la fotografía sobre soporte es una imagen bidimensional que ha transgredido las leyes de la distancia y del tiempo (nosotros tardaríamos mucho tiempo en aproximarnos al lugar real). Ofrece una imagen mutilada y descontextualizada (elimina una gran parte de la información no sólo visual, sino olores, ruidos, temperatura, aquello que nos llega a través de otros sentidos. Tiene dificultades para dar sensación de tridimensionalidad, pero está negando la existencia de la distancia. Según su función, el espacio fotográfico puede ser geométrico o dramático. 
El espacio geométrico es un espacio pasivo, porque contiene la actuación. Puede ser pequeño o grande. A veces fragmenta el encuadre o sintetiza distintos espacios en una misma imagen (fotomontaje) creando un nuevo espacio. Algunos autores, refiriéndose al contenido, utilizan el término 'cerrado' cuando todos los elementos que intervienen en una escena están localizados y se ven dentro del encuadre, o 'abierto' cuando vemos la acción de un personaje que actúa sobre alguien situado fuera del encuadre.

El espacio dramático es todavía más subjetivo que el geométrico. Es activo porque sugiere la acción, expresa el ambiente psicológico en que se encuentran los personajes o el carácter de la acción.

Puede ser opresivo, expansivo o neutro. En los primeros planos o pormenores puede producirse la desaparición del espacio, el encuadre y el ángulo de toma pueden alterarlo.

La fotografía pretenderá más o menos ficticiamente conseguir la tercera dimensión. Por eso se presentará con perspectiva y con volumen. Hay distintos tipos de perspectiva: geométrica, tonal, cromáti$\mathrm{ca}$, focal, cinética. La fotografía empleará todas ellas pero las más específicamente fotográficas son las que utilizan el juego del foco-desenfoque, el barrido y el punto de vista forzado para establecer una distancia espacial entre las figuras que forman la imagen. La holografía ha conseguido un duplicado de la realidad en tres dimensiones, con "auténtico" volumen, y no una imagen plana.

La fotografía no ha sintetizado, ha paralizado, ha detenido el tiempo. A los espectadores les da la oportunidad de explorar, de contemplar lo que ocurre en ese instante detenido, luego está relatando un tiempo cronométrico (además se podría saber en qué año se hizo, o en qué hora del día).

La congelación de un instante es lo más característico de la fotografía y nos ofrece una imagen en la que el modelo está en el contexto donde hizo el gesto (sobre todo en fotografía de prensa). Para el reportaje además es fundamental recoger el instante decisivo, no tanto como para otros tipos de fotografía.

Pero en la fotografía se produce una mezcla de pasado, presente y futuro, y esto es un hecho más psicológico que real, por ello hay que hablar del tiempo dramático de la imagen fotográfica. Roland Barthes sentía ante ciertas fotos lo que él llamaba el punctum (algo que punzaba) y no era producido por simple interés cultural, lo provocaba el tiempo, la interacción entre pasado-presente-futuro. Hasta ahora sólo se ha hablado de imágenes que recogen un solo instante de tiempo cronométrico, aunque de tiempo dramático recojan más. También hay fotografías capaces de captar distintos tiempos cronométricos: fotomontaje, Hockney, series.

La imagen fotográfica puede detener o representar el movimiento y el paso del tiempo de una manera nueva a través de la secuencia fotográfica, la cronofotografía y el fotodinamismo futurista.

La luz, con sus tonos y contrastes, la ausencia o el uso del color, el orden y la composición, la textura y el grano, pueden alterar la percepción de la realidad a través de la imagen y deben ser analizados, pero, por ser elementos mucho más estudiados, simplemente los enumero. 


\section{Análisis de la forma en su contexto}

Para determinados géneros, como el de la fotografía de prensa por ejemplo, el contexto es fundamental para comprender el significado de las imágenes. Habrá que analizar su situación en el medio impreso, en qué página está, en qué lugar de la misma aparece, el tamaño o la cantidad de espacio que ocupa, su formato y su relación con el texto escrito y también si refuerza lo contradice lo que plantea el pié de foto, el título y el subtítulo del artículo al que acompaña y que recursos narrativos o persuasivos utiliza.

Si fueran fotografías artísticas publicadas o con las imágenes publicitarias tendremos en cuenta las particularidades del medio y soporte en que van a ser editadas y, si estuviéramos ante una exposición, no habría que olvidarse de analizar las condiciones ambientales, el orden y las instalaciones que puedan existir en el montaje de la misma, circunstancias que cada vez tienen más importancia y que suelen enriquecer y completar el contenido del relato visual originalmente planteado.

\section{Análisis del contenido}

La forma se analiza para poder comprender mejor lo que nos transmite una imagen y cómo lo hace y si tiene capacidad de comunicación.

Si a través de la foto somos capaces de situarla en el espacio y en el tiempo, establecer el tema y las ideas fundamentales, detectar su estructura, su finalidad fundamental y su funcionamiento de cara a la recepción por parte del espectador, estaremos ante una imagen que merece nuestra atención y que seguramente deberá seleccionarse. Habrá a continuación que pasar a estudiar a los personajes y, sobre todo, al autor. La biografía, las ideas, actitudes, psicología, estilo y evolución nos ayudarán a comprender los motivos que produjeron esa imagen, su relación con la realidad y si hay o no hay manipulación.

Siguiendo este proceso (Casajús, 2001: 616), habremos cumplido nuestro objetivo de reducir más el inmenso número de imágenes producidas. Este método selectivo nos permite a su vez profundizar en la forma y significado de las mismas para poder establecer, y de una manera comparativa, lo que han aportado como documentos, a nivel de lenguaje o por su capacidad creativa, y para, finalmente, poder integrarlas o aislarlas en corrientes estilísticas comunes. Situados en este punto parece más real una posible Historia de la Fotografía.

Aún así, siempre correremos el riesgo de dejar "apartadas" -en el mejor de los casos- imágenes que, por su transcendencia posterior, debieron tenerse en cuenta. Sin embargo, esperemos que el futuro las salve, porque lamentamos que la brillante propuesta de Roy Flukinger (2002), basada en el caos espontáneo, resulte inviable física y económicamente para poder desarrollar la fotohistoria europea. 


\section{REFERENCIAS BIBLIOGRÁFICAS}

- Baeza, P. (2001): Por una función crítica de la fotografía de prensa, Barcelona: Gustavo Gili.

- Burque, P. (2001): Visto y no visto. El uso de la imagen como documento histórico, Barcelona: Crítica.

- Casajús, C. (2001): Historia de la Fotografía de Moda, Madrid: Universidad Complutense de Madrid, p. 616.

- Casajús, C. (1998): Manual de Arte y Fotografía, Madrid: Universitas.

- Costa, J. (1991): La Fotografía. Entre la sumisión y la subversión, México: Edit. Trillas.

- Costa, J. (1977): El lenguaje fotográfico, Madrid: Ibérico Europea de Ediciones.

- Dorfles, G. (1989): Imágenes Interpuestas. De las costumbres al arte, Madrid: Espasa Calpe.

- Durand, R. (1999): El tiempo de la imagen. Ensayo sobre las condiciones de una Historia de las Formas Fotográficas, Salamanca: Ediciones Universidad de Salamanca.

- Flufinger, R. (2002): "Photography for an American Academy". I Congreso Universitario sobre Fotografía Española. Fondo de Publicaciones del Gobierno de Navarra.

- Fontcuberta, J. (1997): El beso de Judas. Fotografía y verdad, Barcelona: Gustavo Gili.

- Fontcuberta, J. (1994): Fotografía: conceptos y procedimientos. Una propuesta metodológica, Barcelona: Gustavo Gili.

- Frizot, M. (2002): La Photographie come non-Histoire de l'Art. I Congreso Universitario sobre Fotografía Española, Fondo de Publicaciones del Gobierno de Navarra.

- Frizot, M., y VVAA (1998): A New History of Photography. Könemann, Édition Adam Biro. (Esta publicación supone la puesta en práctica de la teoría formulada).

- Langford, M. (1996): La fotografía paso a paso, Madrid: Hermann Blume.

- Ledo, M. (1998): Documentalismo Fotográfico, Madrid: Cátedra.

- Sontang, S. (1990): Sobre fotografía, Barcelona: Edhasa.

- Stelzer, O. (1981): Arte y Fotografía. Contactos, influencias y efectos, Barcelona: Gustavo Gili.

- Susperregui, J.M. (1988): Fundamentos de la Fotografía, Universidad del País Vasco.

- Tisseron, S. (2000): El misterio de la cámara lúcida. Fotografía e Inconsciente, Salamanca: Universidad de Salamanca. Salamanca.

- Vilches, L. (1987): Teoría de la imagen periodística, Barcelona: Paidós Comunicación. 
